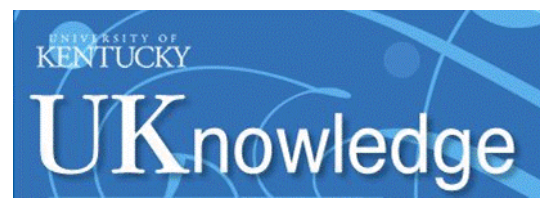

University of Kentucky

UKnowledge

$11-2015$

\title{
Leadership and Mentorship: Service Leaders as Mentors of the Followers
}

Daniel T. L. Shek

University of Kentucky

Li Lin

The Hong Kong Polytechnic University, China

Follow this and additional works at: https://uknowledge.uky.edu/pediatrics_facpub

Part of the Pediatrics Commons

Right click to open a feedback form in a new tab to let us know how this document benefits you.

\section{Repository Citation}

Shek, Daniel T. L. and Lin, Li, "Leadership and Mentorship: Service Leaders as Mentors of the Followers" (2015). Pediatrics Faculty Publications. 199.

https://uknowledge.uky.edu/pediatrics_facpub/199

This Article is brought to you for free and open access by the Pediatrics at UKnowledge. It has been accepted for inclusion in Pediatrics Faculty Publications by an authorized administrator of UKnowledge. For more information, please contact UKnowledge@lsv.uky.edu. 


\section{Leadership and Mentorship: Service Leaders as Mentors of the Followers}

Digital Object Identifier (DOI)

http://dx.doi.org/10.1515/ijdhd-2015-0456

\section{Notes/Citation Information}

Published in International Journal on Disability and Human Development, v. 14, no. 4, p. 351-359.

(c) 2015 Walter de Gruyter GmbH, Berlin/Boston

The copyright holders have granted the permission for posting the article here. 
Daniel T.L. Shek* and Li Lin

\section{Leadership and mentorship: service leaders as mentors of the followers}

DOI 10.1515/ijdhd-2015-0456

Received April 22, 2014; accepted June 23, 2014; previously published online September 17, 2015

\begin{abstract}
According to the Hong Kong Institute of Service Leadership and Management, an effective service leader serves as a mentor for his/her followers. Aside from promoting their followers' professional and personal growth, mentoring also contributes to the development of the service leaders themselves. In this paper, a lecture addressing the concept and functions of mentoring is outlined, along with its relationship with service leadership. The professional and psychosocial functions of mentoring to service leaders and followers and various ways to promote mentoring in service leadership are highlighted. Students are also encouraged to reflect on the potential harmful effects of mentoring on the leader-follower relationship.
\end{abstract}

Keywords: followers; leaders; mentoring; service leadership model.

\section{Introduction}

A mentor usually refers to an individual with advanced experience or in a higher position - one who serves as a role model, provides support, direction, and feedback to an inexperienced individual with regard to career planning and interpersonal development [1]. In an organizational setting, mentoring is described as a kind of social support provided by a senior employee toward another

\footnotetext{
*Corresponding author: Daniel T.L. Shek, PhD, FHKPS, BBS, SBS, JP, Chair Professor of Applied Social Sciences, Department of Applied Social Sciences, The Hong Kong Polytechnic University, Room HJ407, Core H, Hunghom, Hong Kong, P.R. China, E-mail: daniel.shek@polyu.edu.hk; Centre for Innovative Programmes for Adolescents and Families, The Hong Kong Polytechnic University, Hong Kong, P.R. China; Department of Social Work, East China Normal University, Shanghai, P.R. China; Kiang Wu Nursing College of Macau, Macau, P.R. China; and Division of Adolescent Medicine, Kentucky Children's Hospital, University of Kentucky, Lexington, KY, USA

Li Lin: Department of Applied Social Sciences, The Hong Kong

Polytechnic University, Hong Kong, P.R. China
}

employee with less experience and knowledge, in order to enhance the latter's career and personal development [2] In an academic setting, mentoring often occurs between a faculty member and his/her student, in which the former imparts knowledge, provides support, and offers guidance to the latter on academic and personal issues [3]. In the Service Leadership curriculum, a broader definition of mentoring is adopted, which is not limited to career and academic realms, and is extended to any setting where mentors who are more experienced or knowledgeable help with the professional and psychosocial development of novices (i.e. developing others).

According to Kram's [4] mentor role theory, mentoring serves two kinds of functions: career function and psychosocial function. The career function refers to the commitment to providing 'upward mobility and support' in the mentee's career [5, p. 942]. It involves sponsorship (i.e. supporting promotions and later moves), exposure and visibility (i.e. increasing mentee's exposure and visibility in organization), coaching (i.e. coaching mentee in completing tasks), protection (i.e. protecting mentee from adverse influence), and challenging assignments (i.e. providing challenging assignments) [4, 6]. For example, academic mentors can help raise funds for their mentees' research projects. Business mentors can expose their mentees to opportunities by inviting them to join an important event or involving them in significant decisionmaking opportunities. Meanwhile, the function of mentoring can be extended to the personal growth of the mentee, which is called 'psychosocial function'. The psychosocial function pertains to the personal support that 'enhances an individual's sense of competence, identity, and effectiveness in a professional role' [4, p. 32]. It also includes acceptance and confirmation (i.e. cultivating a sense of professional self), counseling (i.e. providing advice for problem-solving), friendship (i.e. offering respect and support), and role modeling (i.e. providing identification and role modeling) [4, 6]. To illustrate, mentors may provide advice to their mentees on personal issues like work-family balance or simply act as a good example of dealing with these issues. Mentors may also instill a positive and realistic self-image into their mentees' mind. Even though leaders may not have formal mentees, their ability to develop others by providing professional support and 
psychosocial support is definitely an attribute of effective leadership.

\section{Mentorship and leadership}

Serving as a mentor for young professionals is a natural component of effective leadership [7, 8]. As asserted by Russell and Nelson, 'true leaders seize the opportunity to develop other people' [8, p. 41]. When developing followers, the leader is also preparing the followers for contributing to the success of the organization. A great leader is usually a great mentor as well.

Contemporary leadership models often regard mentoring as an integral component of leadership. In conceptualizing leadership that aims at serving others (i.e. servant leadership), Greenleaf [9] argued that commitment to the growth of people (i.e. nurturing the personal, professional, and spiritual growth of others) is one of the important services to others. Spears [10] also believed that serving others includes taking the responsibility to nurture the professional and personal growth of others. One of the important characteristics of servant leaders is related to their role in facilitating the growth of others, which refers to 'an ability to identify others' needs and provide developmental opportunities' [11, p. 308]. This is exactly what a mentor should do. In addition to servant leaders, mentoring behavior is encouraged in transformational leadership as well. As Stone, Russell and Patterson noted, 'both transformational leadership and servant leadership emphasize the importance of appreciating and valuing people, listening, mentoring or teaching, and empowering followers' [12, p. 4]. For example, the typical behavior of transformational leadership includes idealized influence, which entails serving as a role model for followers to emulate. Another mentoring behavior, individualized consideration, involves acting as a mentor to listen and respond to followers' concerns and needs. These theories suggest that mentoring others is required in achieving effective leadership.

The significance of mentoring is also exemplified in the real organizational settings. In the Project Oxygen, researchers in Google Inc. identified eight good behaviors of managers whose team members performed better, retained longer, and felt happier. Two of these behaviors closely related to mentoring are 'being a good coach' and 'helping your employees with career development' [13]. Additionally, students themselves may also gain some experience of leading while mentoring others in university life. For example, senior students with excellent performance in the service learning courses would serve as student leaders in later service learning activities. They can lead a group of younger students to finish the service tasks while coaching and supporting them in the process. Mentoring others is a naturally occurring phenomenon in daily life.

In brief, both theories and actual events have indicated that mentoring is an integral part of leadership. According to the Service Leadership and Management framework (SLAM) proposed by the Hong Kong Institute of Service Leadership and Management [14], service leaders need to know 'how to use a variety of master/apprentice, mentor/mentee, and coaching approaches to improve the Service Leadership competencies, character strengths, and caring disposition of others'. It implies the mission of service leaders as nurturing and developing other's competencies, character, and caring disposition. Therefore, corresponding education is necessary in order to nurture these effective service leaders. Once students recognize the crucial role of mentoring in leadership, they are more likely to demonstrate mentoring behavior in their leadership [6].

Despite the encouragement of mentoring behaviors implicitly or explicitly in modern leadership models [11, $12,14]$, the importance of taking a mentoring role in a leadership process appears to be a missing part in leadership education and training. Much of the education aims at nurturing students' skills to manage and influence others, while there is a lack of education emphasizing what, how, and why there is a need to develop mentoring as a leadership skill. Additionally, there is an old Chinese saying that 'if the mentor imparts all the knowledge and skill to the apprentice, he/she will be starved to death' (jiao hui tu di, e si shi fu), which discourages fully developing others. Against this background, the SLAM education attempts to fill this gap by offering students with knowledge about mentoring and opportunities to improve their mentoring skills.

\section{The benefits of mentoring}

A mentoring relationship involves reciprocal benefits and mutual learning between mentor and mentee [6]. To begin with, a large body of evidence suggests that mentoring is conducive to the career development and psychosocial adjustment of mentees [15-17]. Mentoring can facilitate mentees' career development, such as increasing income and upward mobility as well as expanding social network. It can also enhance mentees' psychosocial adjustment, such as enhancing their job satisfaction and motivation, career commitment, sense of competence, and ability 
to reduce distress. To illustrate, in a longitudinal study assessing mentors and mentees' outcomes of a formal mentoring program, mentors' professional support predicted heightened emotional well-being and commitment to the organization of mentees [18]. Informal mentoring brings even more satisfying outcomes to mentees' career development and psychosocial adjustment, which may possibly be due to a closer relationship and mutual identification with the relationship [19] or altruistic nature of informal mentoring [7]. With the help of mentors, the mentees would grow faster than their peers. More importantly, they would have a better emotional adjustment and stronger commitment to the career and even the organization.

Aside from gains for the mentees, emerging research has also shown the beneficial outcomes from the perspective of the mentor [20, 21]. Mentoring others possibly improves mentors' job performance and social status, increases their visibility and recognition in the organization, brings about self-satisfaction due to the success in developing others, and helps foster closer work relationship and obtain loyalty from the mentees [20-24]. Allen, Lentz, and Day [22] compared career development of people who ever served as an informal mentor with those having little experience. Results showed that the mentoring experience is positively associated with salary growth, promotion rate, and self-perception of career success beyond the effect of demographic variables (i.e. gender, age, race, education, organizational tenure, hours worked). In addition, mentors could also obtain benefits from 'reverse mentoring' [25]. It is possible that the young and well-educated novice shares the latest technology information or other latest knowledge with the mentor, and assists in the mentor's work, which in turn, stimulates the latter's self-improvement [24]. The responsibility of being a good role model also stimulates mentors to adjust and improve themselves [8]. The interaction between mentor and mentee makes the beneficial outcomes of mentoring experience powerful and enduring [7].

Notwithstanding the numerous reported benefits of mentoring, mentoring is not risk-free. As noted by Carr and Heiden [26], mentoring might not necessarily be a 'bright phenomenon'. Negative mentoring experience exists and has been found to adversely affect the parties involved [6, 27, 28]. Eby, Butts, Lockwood, and Simon [27] contended that dysfunctional mentoring experience occurs because of the following reasons: 1) mismatch between mentor and mentee (e.g. personality, work style and values), 2) mentors' distancing behaviors (e.g. excluding the mentee from important events), 3) mentors' manipulative behaviors (e.g. tyranny, credit-taking and deception), 4) lack of mentor expertise (e.g. lack of ability to support mentee), and 5) general dysfunctionality (e.g. mentors' personal problem). Dwyer [29] also believed that not every mentoring program can be considered effective. Instead, mentors who are not well prepared possibly bring suffering rather than benefits to the mentees. She identified the seven 'deadly sins of mentorship' in a mentoring program, which include ignorance of improving mentoring skills, over reliance on preaching, acquiescence on mentees' problem avoidance, over concentration on disclosing one's own anecdotes, generalizing the issue in teaching mentees, and lack of consensus in objectives and ground rules. Even the closeness of a mentor-mentee relationship itself implies potential risks, such as making the relationship more personal and less professional [7]. These 'deadly sins' might not solely be attributed to mentors' problems. Instead, the whole communication process between the two parties involved should be taken into account [26].

More importantly, these dysfunctional mentoring experiences negatively affect mentees' career and psychosocial life. An initial study [30] pointed out that mentor's intentional exclusion, mentor's general abuse of power, mismatched personality between the mentor and mentee, and mentor's interpersonal incompetence are associated with lower job satisfaction, higher turnover intention, and greater stress of mentees. Eby et al. [28] even found that negative mentoring could predict mentee outcomes over and above positive mentoring. For example, a mentor's general dysfunctional features predict greater intention for the mentees to leave the relationship; manipulative behavior also predicts the depressed mood of the mentees. Additionally, the interpersonal problems of the mentormentee relationship would also increase the burnout of mentors, while the mentees' performance problems would make the mentors more likely to quit the relationship [31]. Accordingly, both mentors and mentees suffer from such negative mentoring experience.

A positive mentoring experience would be fruitful, whereas a negative mentoring experience would be destructive. It is important to recognize that, in addition to the advantages of mentoring, there may be problems and risks involved. From a different angle, the dark side of mentoring experience indicates that it is significant for a service leader to learn how to be a good mentor so that detrimental experience could be minimized.

\section{The characteristics of a good mentor}

There are diverse views concerning what a good mentor should be. When developing the ideal mentor scale, Rose 
[32] identified three factors underlying an ideal mentor from the perspective of $\mathrm{PhD}$ students. These factors included the expression of individualized care and concern to the students, the provision of practical and hands-on help, and the establishment of a positive and personal mentor-mentee relationship. In particular, the ability to communicate effectively with students and the provision of honest feedback were appreciated by the majority of the students. Similarly, Cho et al. [33] found that students of health science perceived outstanding mentors as the ones showing desirable personal attributes, such as being compassionate, enthusiastic, generous, and honest. In addition, he/she provides professional and specific support while delivering a vision to his/her mentee; makes strong time commitment by having regular, frequent and highquality meetings; supports professional and personal balance; and serves as a role model for mentees and other colleagues providing mentorship.

In the review of literature about peer mentorship, Terrion and Leonard [34] found the following eight primary characteristics of outstanding peer mentors: effective communication skills, supportiveness, trustworthiness, interdependency in attitudes, empathy, personality match with mentee, enthusiasm, and flexibility. Mentors themselves also reported their understanding of ideal mentors in the extant literature. From the perspective of mentors in the academic, business, military and military-academic fields, ideal mentor characteristics could be categorized into respectability, wisdom, and sensitivity [35]. Respectability refers to the morality of mentors like honesty and integrity, wisdom entails professional competence and ability to teach, while sensitivity involves empathy and compassion. In an interview of 27 mentors in the business sector, Allen and Poteet [36] found that the five most frequently mentioned qualities of an ideal mentor include the following: listening and communication skills, patience, knowledge of organization and industry, ability to read and understand others, and honesty. From the above descriptions, we can see that most of the characteristics of ideal mentors are related to the three components of effective service leadership: competencies (e.g. communication skills and knowledge about the organization), moral character (e.g. integrity and trustworthiness), and caring disposition (empathy and listening). A good mentor not only equips him/herself with expert knowledge and skills, but also possesses the ability to coach or teach others. As noted by Sosik and Lee, "being perceived as an effective "teacher" may enhance mentoring functions provided' [2, p. 26].

Furthermore, given that setting good examples to be emulated by the mentees is one of the critical objectives of being a mentor [8], he/she needs to possess desirable personal qualities, such as integrity and care. Acting ethically and demonstrating care may foster the mentees' loyalty and commitment to the relationship. Moral character and caring disposition might be more important than the competencies of mentors, as revealed by the study of Smith et al. [35], in which mentors attached more importance to respectability and sensitivity than wisdom. It is in line with the SLAM educational principle that places more emphasis on the education of moral character and caring disposition than the competencies of leaders. One of the basic assumptions of the SLAM framework is that these three components of effective leadership are learnable, and thus nurturing students to be good mentors becomes the next important step.

\section{Ways to improve mentoring}

Mentoring is important to both a service leader and his/ her mentee, and thus it is necessary to figure out ways to improve effective mentoring. To effectively facilitate professional development, cognitive apprenticeship is recommended. Traditionally, mentees learn from observing what mentors do. However, many modern professional skills are relatively tacit (e.g. writing). Mentoring through cognitive apprentice requires making tacit cognitive process visible to mentees so that the mentees can observe and practice them [37]. Mentors are encouraged to adopt cognitive apprenticeship through modeling (i.e. demonstrating the temporal thinking process), explanation (i.e. explaining the underlying rationale or reason of activities), coaching (i.e. monitoring mentee's activities and providing assistance and support when necessary), scaffolding (i.e. assisting the mentee in a certain task and gradually withdrawal the task), reflection (i.e. asking the mentee to rate and analyze his/her performance), articulation (i.e. asking the mentee to articulate his/her reflection), and exploration (i.e. allowing mentee to work independently and explore their new ideas). The cognitive apprenticeship model requires that a mentor should possess high meta-cognitive ability, because the mentor should be aware of the whole cognitive process before communicating to the mentee.

To effectively provide psychosocial support, selfdisclosure and trust construction are highlighted. Hart [38] believed that successful mentoring rests on the rapport, collaboration, trust, respect, and commitment between the mentor and mentee. Therefore, building a good mentormentee relationship is conducive to effective mentoring. Hart [38] further suggested several approaches to build and manage the mentoring relationship, in which we would 
highlight self-disclosure and trust building. Mentors' sharing of personal experience and feelings enables mentees to better manage their own situations. Showing a realistic self to the mentees also adds to building a trustful relationship. Furthermore, mentors are encouraged to affirm the uniqueness and strengths of the mentees; provide honest, direct, caring, and prompt evaluation on the mentees; keep calm when error occurs; actively listen to the viewpoints of mentee; and try to understand from their perspectives. It is expected that these practices would positively contribute to a trustful and pleasant mentor-mentee relationship. As there are a variety of ways to improve mentoring skills, students are encouraged to reflect on their own problems and think out their own solutions.

\section{Lecture content}

Notwithstanding the merits of mentoring others in the effective leadership, extant leadership education seldom emphasizes this important component. Based on the previous literature, The Hong Kong Polytechnic University has developed a lecture under the topic of 'leaders as mentors' in the course 'Service Leadership'. The rationale, learning goals, teaching methods, as well as lecture plan are presented as follows.

Mentoring refers to senior persons coaching, guiding, supporting and role-modeling to young or inexperienced persons. An essential part of being a leader is to mentor others. Mentoring serves to enhance mentees' professional development and psychosocial adjustment. Meanwhile, it also benefits the mentors. In service leadership, developing others by mentoring is particularly important because one could improve his/her leadership competencies, moral character and caring disposition through a variety of mentoring approaches. This lecture introduces the key concepts of mentor/mentoring, and explain the importance of mentoring to service leadership, mentees and mentors. In order to enhance the effectiveness of mentoring among students, this lecture will also discuss ways to improve mentoring. In addition, the dark side of mentoring will be mentioned as well during the learning process.

It is expected that after taking this lecture, the students will be able to: a) understand the concept and the nature of mentor, $b$ ) recognize the relevance of mentoring others to a service leader, c) understand the professional and psychosocial functions of mentoring to both mentees and mentors, and e) explore ways to promote the professional and psychosocial functions of mentoring.
In this lecture, class activities, including group discussion and self-reflection, are incorporated into the lecture. The lecture plan is presented below.

\begin{tabular}{ll}
\hline & Teaching content \\
\hline Part 1: Introduction of & - Lecture \\
mentor/mentorship & - Class Activity: “Thank You Card” \\
Part 2: The Relationship & - Lecture \\
with service leadership & \\
Part 3: Win-win of & - Lecture \\
mentoring & - Group Discussion: "Is It Easy to Be a \\
& Good Mentor?" \\
Part 4: How to be a & - Lecture \\
good mentor? & - Self-reflection: "Can I Be a Good \\
Part 5: Conclusion & Mentor?" \\
\hline
\end{tabular}

At the beginning of the lecture, students are presented with a picture, in which a black figure is holding a white figure up. Students are asked which person would be a good leader. Through reflecting on this question, the teacher introduces the main theme of this lecturs - leaders could act as mentors who help others move upward.

For the first learning goal, the definition and functions of mentor/mentoring are introduced to students. Kram's [4] mentor role theory is introduced and the four roles of a mentor are highlighted, including the role of teacher to coach mentees, the role of counselor to guide mentees, the role of friend to support mentees, and the role of role model to set good examples for mentees. The teacher should also highlight that given the multiple roles of mentor, not only the one with excellent professional knowledge and skills can be a mentor. For example, a person with strong moral character can be a mentor influencing and guiding others.

In order to facilitate students' understanding of mentor and mentoring, a class activity called 'Thank You Card' is conducted. Each student is given a worksheet in the form of a thank you card, and is required to write an acknowledgment to any person who ever took a mentoring role in his/her life (see Worksheet 1). Through visualizing mentoring and linking the four roles of mentor to students' daily life, the students will find this concept meaningful and the knowledge useful to them. The selfreflection activity is wrapped up by concluding that mentoring occurs in diverse domains and can contribute to one's professional and personal growth.

For the second learning goal, the relationship between mentoring and service leadership is discussed. Two important knowledge points are introduced here. First, it 
is asserted that mentoring is an integral part of effective leadership. By teaching this part, teachers can guide students to compare the tasks of mentors and service leaders as well as identify the overlapping duties. One characteristic of a service leader is the commitment to the growth of others, which is related to mentoring others. Mentoring is one of the essential skills in service leadership and it helps improve others' leadership competencies, caring disposition, and moral character. Students are guided to understand that mentoring others is part of their leadership practice; emphasizing mentoring work as part of leadership role would encourage higher engagement in mentoring behavior among the students [6]. In addition, mentoring also serves to improve oneself through continuous learning. This part of the lesson is wrapped up by highlighting that mentoring others echoes the essential characteristic of service leadership - providing quality service to satisfy the needs of others as well as self.

For the third learning goal, the benefits of mentoring to both mentees and mentors are discussed. As mentoring has professional and psychosocial functions, the benefits of mentoring are categorized into two groups (i.e. professional support and psychosocial support). It is natural for students to expect benefits for the mentees, but it is important to make students aware of the gains for the mentors as well. As mentoring others requires great investment of time and effort, awareness of the reciprocity in the mentoring relationship would motivate students to take an effective mentoring role in their lives and future leadership. Specifically, teacher guides students to think of how the mentoring practices improve their leadership competencies, caring disposition, and moral character.

To help students fully understand that mentoring work includes benefits and difficulties, a group activity named 'Is It Easy to Be a Good Mentor?' is conducted. Each group of students is assigned with a scenario in which there is a conflict or problem occurring in the mentoring relationship (see Appendix 1). Students then discuss a solution with their group mates, specifically with regards to being a good mentor. They are guided to make use of leadership competencies, caring disposition, and moral character to solve the problem. This activity enables students to understand the difficulties of being a mentor and provokes their thinking about how they can become good mentors. The activity is wrapped up by concluding that mentoring others is a challenge and an opportunity, which requires one to continually explore ways to improve it.

For the fourth learning goal, several approaches to improve mentoring effectiveness are introduced. Based on the mentor role theory, the teacher introduces various approaches related with professional support and psychosocial support. For professional development, cognitive apprenticeship is introduced with an emphasis on articulating thinking processes in mentoring. Students are guided to learn some specific practices in cognitive apprenticeship. For psychosocial support, self-disclosure and building trust are introduced, with an emphasis on creating a good relationship between the mentor and mentee. Students are guided to understand how selfdisclosure and trust contribute to effective mentoring and how to make appropriate self-disclosure and build trusting mentoring relationship.

Before introducing ways for improvement, a selfreflection exercise is conducted. By finishing a worksheet (see Worksheet 2), students are invited to think of the three most important characteristics for a service leader in their profession, and rate themselves on each important characteristic. Relating the knowledge to students' profession will make the knowledge comprehensible and meaningful. In addition, a self-reflection exercise could provoke students' introspection and guide their subsequent selfimprovement practice.

Finally, the lecture is wrapped up by highlighting the mutual benefits of mentoring to both service leaders and their followers. In addition, students are led to discuss the link between this lecture and the core beliefs of service leadership.

Nevertheless, during the learning process, students should be led to understand the shadows and potential damage of mentorship as well. According to Carr and Heiden [26], while there are many benefits of mentoring, mentoring might have a number of potential problems (i.e. dark side), such as role confusion, conflicts amongst colleagues, erosion of individual autonomy, and conflicting organizational culture. Long [39] similarly highlighted the negative aspects of mentoring. Hence, mentors should be sensitive to the nature of relationship between the mentors and mentees, such as exploiting the mentees and creation of dependence of the mentees on the mentors. In addition, the mentor should be aware of the potential damaging effect of transference in the dyad. In the broader context of the organization, mentoring may also create clans and inter-group conflict as well as jealousy and favoritism. Therefore, regular review of the mentor-mentee relationship is important for its healthy sustainability. When to stop the mentor-mentee relationship should also be considered. The awareness of the dark side of mentoring helps students build a constructive mentoring relationship.

In conclusion, a quotation by American industrialist Harvey S. Firestone that 'it is only when we develop others that we permanently succeed' would be shared with the students. 


\section{Worksheet 1}

Preparing a Thank you Card for Your Mentor

$-8$

$-8$

$-8$

\begin{tabular}{||l|l|l|} 
Thank You For Being Such A Great Mentor, And Making My Life Meaningful \\
Thank you for \\
\hline It makes me feel
\end{tabular}

\section{Worksheet 2}

\section{Can I be A Good Mentor?}

O What is your major or expected profession?

What kind of characteristics do you think are important to be a mentor in your expected profession?

\begin{tabular}{|l|l|l|l|l|l|l|}
\hline $\begin{array}{l}\text { Please list three } \\
\text { characteristics }\end{array}$ & $\begin{array}{l}\text { Is it related to Competence, Care, or Moral } \\
\text { Character }\end{array}$ & \multicolumn{5}{|l|}{ To what extent, do you possess these characteristics? } \\
\hline & & Very weak & & & & Very strong \\
\hline & & 1 & 2 & 3 & 4 & 5 \\
\hline & & 1 & 2 & 3 & 4 & 5 \\
\hline & & 1 & 2 & 3 & 4 & 5 \\
\hline
\end{tabular}




\section{Appendix 1}

\section{Practices for Being a Good Mentor}

Request each group to draw one from the following scenarios and discuss what a good mentor should do in that situation, according to their understanding and imagination. Then invite each group to role-play the scenario based on the results of the discussion.

Scenario A

You are leading a team in a logistic company. One day, you requested a member of your team, Johnny, to file the documents according to your instructions. However, Johnny thought that the filing system you created was inflexible and inefficient. He cried, 'I do think the filing system is outdated!'

What should you do?

Scenario B

You and your mentee, Luana, work together in a market research company. Some of your colleagues have resigned recently. Then, your boss promised Luana that he would increase her salary and employ more staff members to cope with the heavy workload. However, your boss did not act up to his promises. Luana was angry and asked you to argue with the boss, 'You have to fight for me!'

What should you do?

Scenario C

Tracy and Patrick are students of The Hong Kong Polytechnic University. They have a six-month work placement in your company and you are their mentor. One day, you accidently overheard a conversation between them:

'Patrick, what are you doing now?'

'I have nothing to do at this moment. Tracy, how about you?'

'The mentor is unfair! I need to finish three to four tasks within this week'.

In fact, Patrick has nothing to do because his work is to be assigned later. However, it may not be advisable to explain to them as they did not expect you to overhear the conversation.

What should you do?

\section{Scenario D}

Michelle is a student of The Hong Kong Polytechnic University. She has a six-month work placement in your company and you are her mentor. She will be the emcee of the international symposium held by your company. However, she stammers every time when she has to make a speech in public. One day, Michelle expressed her anxiety to you, 'I am so anxious that I could not sleep well at night!'

What should you do?

\section{Scenario E:}

You and your team members are celebrating at a Christmas party. Everyone shares their personal feelings about being a staff of this company. Suddenly your mentee, Chloe, smiles and says, 'My mentor is quite good. He is a nice guy. However, other colleagues told me Amy is better. Comparing to my mentor, Amy's instructions are clearer and she has excellent time management skill.' What should you do?

\section{References}

1. Day R, Allen TD. The relationship between career motivation and self-efficacy with protégés career success. J Vocat Behav 2004;64:72-91.

2. Sosik JJ, Lee DL. Mentoring in organizations: a social judgment perspective for developing tomorrow's leaders. J Leadersh Organ Stud 2002;8:17-32.

3. Jacobi M. Mentoring and undergraduate academic success: a literature review. Rev Educ Res 1991;61:505-32.

4. Kram KE. Mentoring at work: developmental relationships in organizational life. Glenview, IL: Scott Foresman, 1985.

5. Ragins BR, Cotton JL. Easier said than done: gender differences in perceived barriers to gaining a mentor. Acad Manage J 1991;34:939-51.

6. Haggard DL, Dougherty TW, Turban DB, Wilbanks JE. Who is a mentor? A review of evolving definitions and implications for research. J Manage 2011;37:280-304.

7. Gibson JW, Tesone DV, Buchalski RM. The leader as mentor. J Leadersh Organ Stud 2000;7:56-67.

8. Russell JS, Nelson J. Completing the circle of professional development through leadership and mentoring. Leadersh Manag Eng 2009;9:40-2.

9. Greenleaf RK. The power of servant leadership. San Francisco, CA: Berrett-Koehler, 1998.

10. Spears LC. Practicing servant-leadership. Leader to Leader 2004;2004:7-11.

11. Barbuto JE, Wheeler DW. Scale development and construct clarification of servant leadership. Group Organ Manage 2006;31:300-26.

12. Stone AG, Russell RF, Patterson K. Transformational versus servant leadership: a difference in leader focus. Leadership Organ Dev J 2004;25:349-61. 
13. Bryan A. Google's quest to build a better boss. New York Times 2011 March 12. URL: http://www.nytimes.com/2011/03/13/ business/13hire.html?_r=2\&.

14. Hong Kong Institute of Service Leadership and Management. SLAM education, 2013. URL: http://hki-slam.org/

15. Allen TD, Eby LT, Poteet ML, Lentz E, Lima L. Career benefits associated with mentoring for protégés: a meta-analysis. J Appl Psychol 2004;89:127-36.

16. Eby LT, Allen TD, Evans SC, Ng T, DuBois D. Does mentoring matter? A multidisciplinary meta-analysis comparing mentored and non-mentored individuals. J Vocat Behav 2008;72:254-67.

17. Sosik JJ, Godshalk VM. Leadership styles, mentoring functions received, and job-related stress: a conceptual model and preliminary study. J Organ Behav 2000;21:365-90.

18. Chun JU, Sosik JJ, Yun NY. A longitudinal study of mentor and protégé outcomes in formal mentoring relationships. J Organ Behav 2012;33:1071-94.

19. Ragins BR, Cotton JL. Mentor functions and outcomes: a comparison of men and women in formal and informal mentoring relationships. J Appl Psychol 1999;84:529-50.

20. Allen TD. Mentoring relationships from the perspective of the mentor. In: Ragins BR, Kram KE, editors. The handbook of mentoring at work: theory, research, and practice. Thousand Oaks, CA: Sage, 2007:123-47.

21. Allen TD, Poteet ML, Burroughs SM. The mentor's perspective: a qualitative inquiry and future research agenda. J Vocat Behav 1997;51:70-89.

22. Allen TD, Lentz E, Day R. Career success outcomes associated with mentoring others: a comparison of mentors and nonmentors. J Career Dev 2006;32:272-85.

23. Eby LT, Durley JR, Evans SC, Ragins BR. The relationship between short-term mentoring benefits and long-term mentor outcomes. J Vocat Behav 2006;69:424-44.

24. Liu D, Liu J, Kwan HK, Mao Y. What can I gain as a mentor? The effect of mentoring on the job performance and social status of mentors in China. J Occup Organ Psych 2009;82:871-95.

25. Greengard S. Moving forward with reverse mentoring. Workforce 2002;81:15.

26. Carr K, Heiden EP. Revealing darkness through light: communicatively managing the dark side of mentoring relationships in organisations. Aust J Commun 2011;38:89-104.
27. Eby LT, McManus SE, Simon SA, Russell JE. The protege's perspective regarding negative mentoring experiences: the development of a taxonomy. J Vocat Behav 2000;57:1-21.

28. Eby L, Buits M, Lockwood A, Simon SA. Protégés negative mentoring experiences: construct development and nomological validation. Pers Psychol 2004;57:411-47.

29. Dwyer K. Deadly sins of mentorship. Available at: http://www. changefactory.com.au/articles/human-resource-management/ seven-deadly-sins-of-mentoring.

30. Eby LT, Allen TD. Further investigation of protégés' negative mentoring experiences patterns and outcomes. Group Organ Manage 2002;27:456-79.

31. Eby LT, Durley JR, Evans SC, Ragins BR. Mentors' perceptions of negative mentoring experiences: scale development and nomological validation. J Appl Psychol 2008;93:358-73.

32. Rose GL. Group differences in graduate students' concepts of the ideal mentor. Res High Educ 2005;46:53-80.

33. Cho CS, Ramanan RA, Feldman MD. Defining the ideal qualities of mentorship: a qualitative analysis of the characteristics of outstanding mentors. Am J Med 2011;124:453-8.

34. Terrion JL, Leonard D. A taxonomy of the characteristics of student peer mentors in higher education: findings from a literature review. Mentor Tutor: Pract Learn. 2007;15: 149-64.

35. Smith WJ, Howard JT, Harrington KV. Essential formal mentor characteristics and functions in governmental and nongovernmental organizations from the program administrator's and the mentor's perspective. Public Pers Manage 2005;34:31-58.

36. Allen TD, Poteet ML. Developing effective mentoring relationships: strategies from the mentor's viewpoint. Career Dev Q 1999;48:59-73.

37. Collins A, Brown JS, Holum A. Cognitive apprenticeship: making thinking visible. Am Educ 1991;15:38-46.

38. Hart EW, editor. Seven keys to successful mentoring. Center for Creative Leadership, 2009. URL: http://web.ebscohost.com/ ehost $/$ detail ?vid=4\&hid=11\&sid=f6be31a3-a454-48a1-8d478fc36fb2a837\%40sessionmgr115\&bdata=JnNpdGU9ZWhvc3Qtb Gl2ZQ\%3d\%3d\#db=bth\&AN=43659167.

39. Long J. The dark side of mentoring. Aust Educ Res 1997;24: 115-33. 